Supporting Information

\title{
Persistent Negative Compressibility Coupled to Optical Modulation in Empty-Perovskite $\mathrm{TiOF}_{2}$
}

Yang Lu, ${ }^{\dagger} *$ Hao Yan, ${ }^{\ddagger}$ Eugene Huang, ${ }^{\dagger}$ Bin Chen $^{\dagger}$

${ }^{\dagger}$ Center for High Pressure Science \& Technology Advanced Research, Shanghai 201203, China

$¥$ CAS Key Laboratory of Experimental Study under Deep-sea Extreme Conditions, Institute of Deep-Sea Science and Engineering, Chinese Academy of Sciences, Sanya 572000, China

E-mail: yang.lu@hpstar.ac.cn

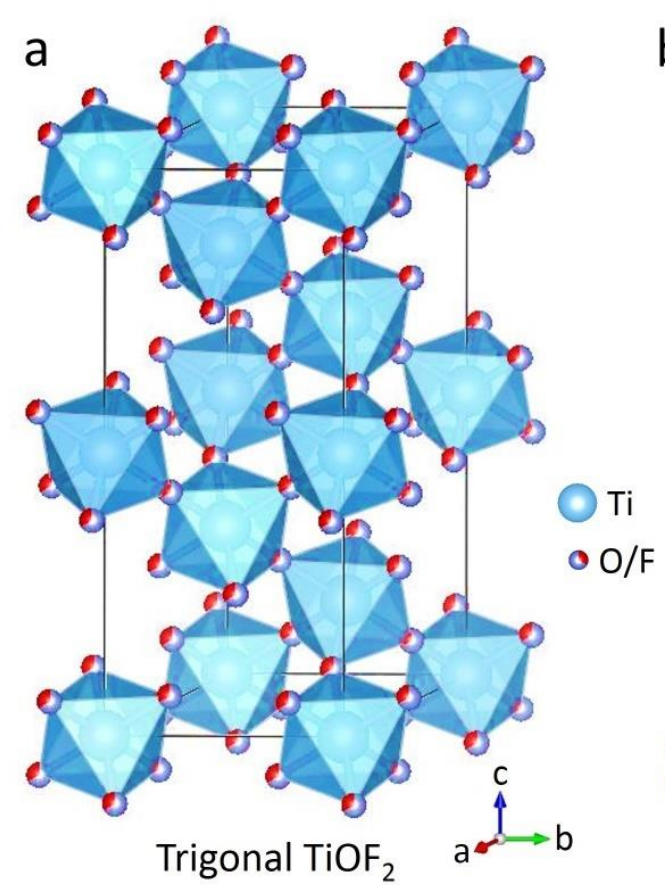

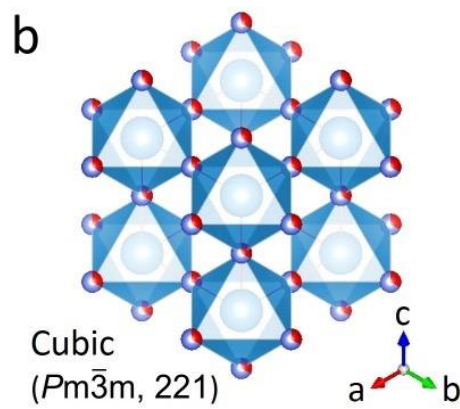

(Pm3̄m, 221)

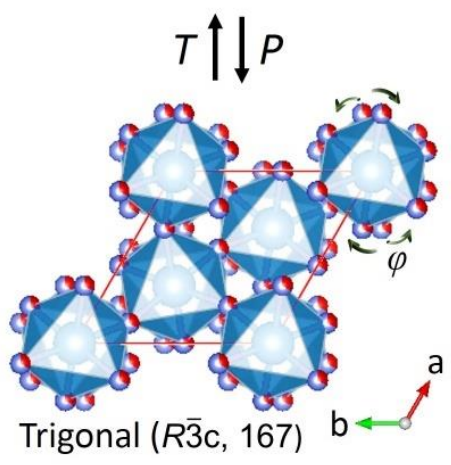

Figure S1. (a) Crystal structure of trigonal $\mathrm{TiOF}_{2}$. (b) Phase transition between cubic and trigonal $\mathrm{TiOF}_{2}$ viewed from the $[111]_{\text {cubid }} /[0001]_{\text {Trigonal }}$ direction. $\varphi$ represents the rotation angle of $\left[\mathrm{TiO}_{2} \mathrm{~F}_{4}\right]$ octahedra along the $c$-axis after the cubic-to-trigonal phase transition. 

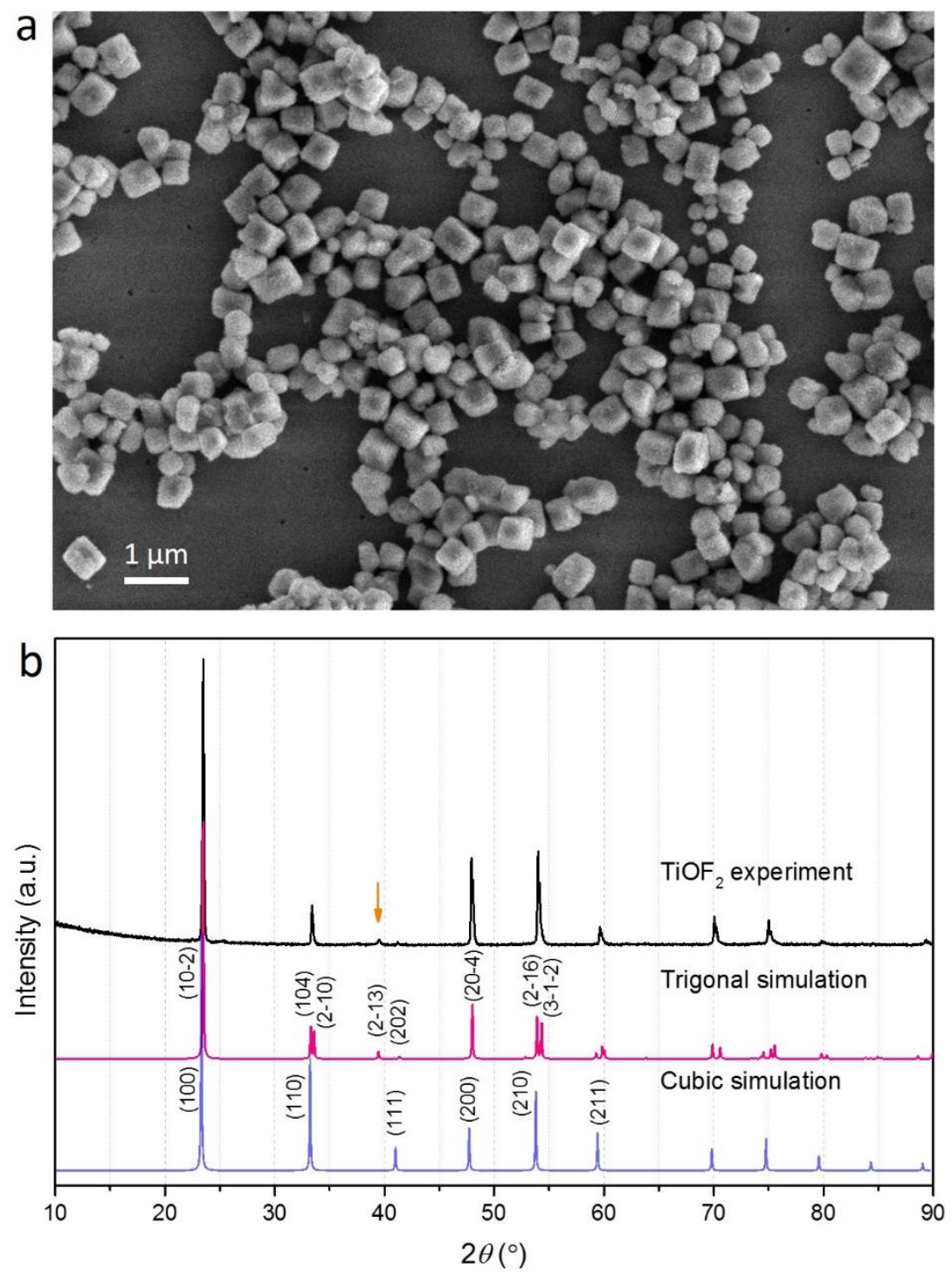

Figure S2. (a) SEM image of pristine $\mathrm{TiOF}_{2}$ nanoparticles. (b) XRD pattern of the starting $\mathrm{TiOF}_{2}$ materials at ambient conditions compared with the XRD simulations of trigonal and cubic structures $\left(\lambda_{\mathrm{Cu} \mathrm{K} \alpha 1}=1.540598 \AA\right.$ ). 

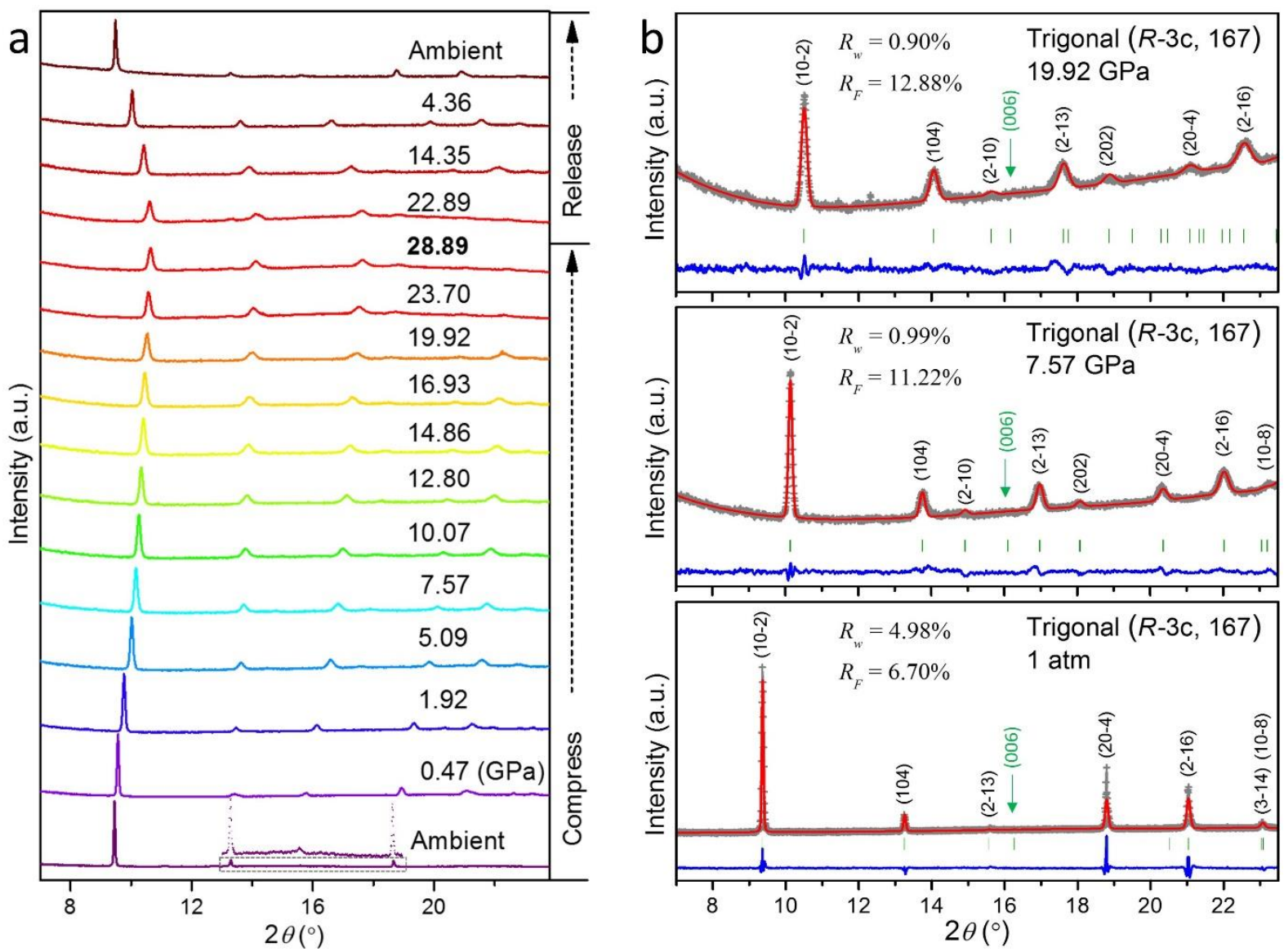

Figure S3. (a) Synchrotron $\mathrm{X}$-ray diffraction patterns of $\mathrm{TiOF}_{2}$ under compression and decompression $(\lambda=0.6199 \AA)$. The selected retangular region of the ambient pattern is enlarged. (b) Rietveld refinements of the synchrotron XRD spectra of the sample at $1 \mathrm{~atm}, 7.57 \mathrm{GPa}$, and 19.92 GPa. The blue lines denote the difference between the experiments (gray crosses) and refinements (red lines), and the green vertical lines represent the refined peak positions. 

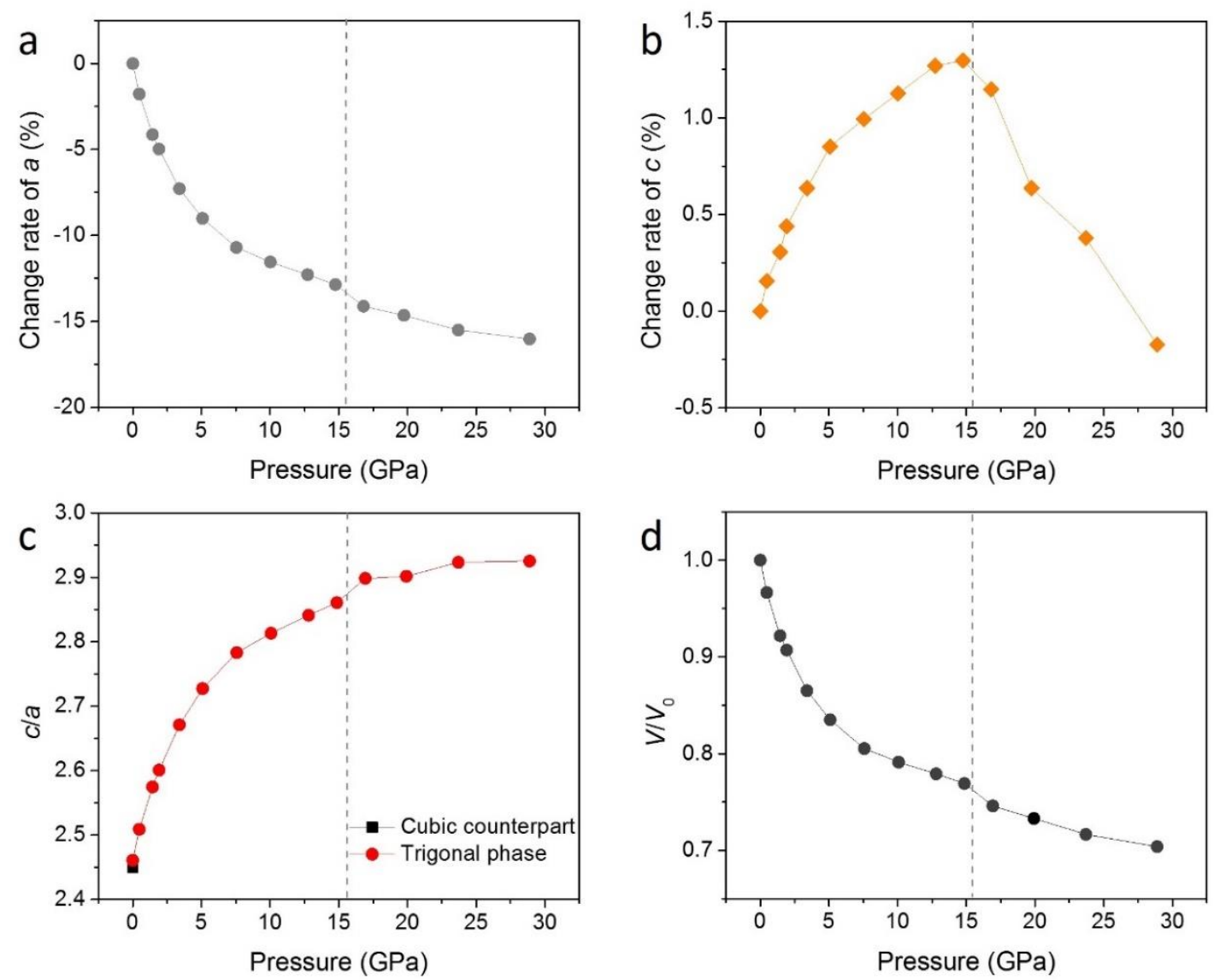

Figure S4. Pressure-dependent change rates of $a$ and $c$ (a and b), $c / a$ (cubic counterpart: $\sqrt{6}$ ) (c), and $V / V_{0}(\mathrm{~d})$ of $\mathrm{TiOF}_{2}$. 


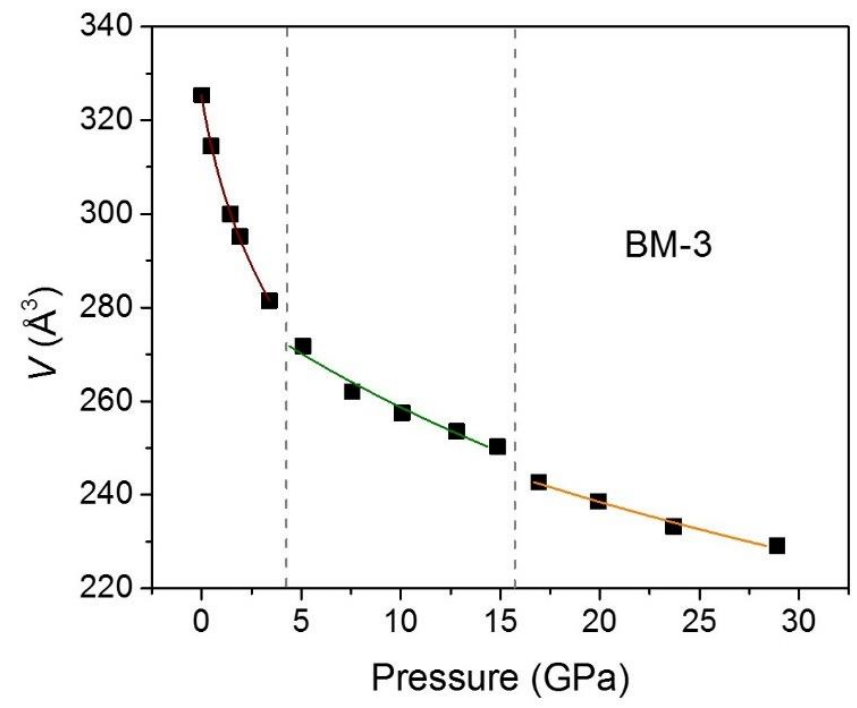

Figure S5. Pressure-dependent unit cell volume of $\mathrm{TiOF}_{2}$. The relationship between the volume and pressure were fitted by the $3^{\text {rd }}$-order Birch-Murnaghan (BM3) equation of state (EOS) $P(V)=3 B_{0} f_{E}\left(1+2 f_{E}\right)^{5 / 2}\left[1+\frac{3}{2}\left(B_{0}^{\prime}-4\right) f_{E}\right]$ where $f_{E}=\left[\left(V_{0} / V\right)^{2 / 3}-1\right] / 2$ is the Eulerian strain, $B_{0}$ is the bulk modulus, $B_{0}$ is its pressure derivative, and $v$ and $V_{0}$ are the unit cell volume and volume at zero pressure.

Table S1. BM3-EOS parameters of $\mathrm{TiOF}_{2}$.

\begin{tabular}{cccc}
\hline Pressure range $(\mathrm{GPa})$ & $B_{0}(\mathrm{GPa})$ & $B_{0}^{\prime}$ & $V_{0}\left(\AA^{3}\right)$ \\
\hline $0-4$ & 12.74 & 9.22 & 325.07 \\
$4-15$ & 86.15 & 4 (fix) & 284.70 \\
$15-30$ & 118.38 & 4 (fix) & 271.62 \\
\hline
\end{tabular}



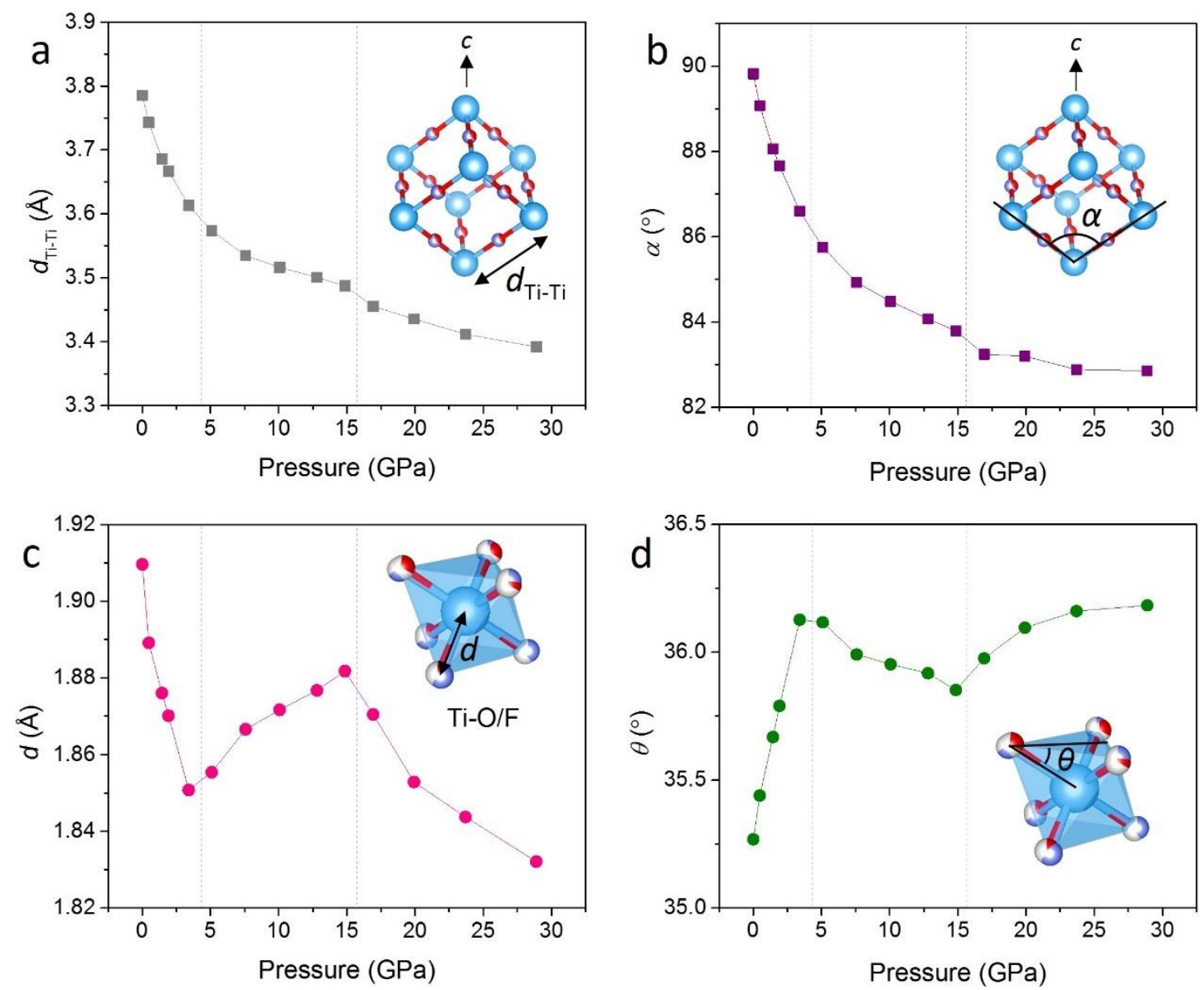

Figure S6. Pressure-dependent nearest-neighbor Ti $\cdots$ Ti distance $\left(d_{\mathrm{Ti}-\mathrm{Ti}}=\sqrt{\left(\frac{a}{\sqrt{3}}\right)^{2}+\left(\frac{c}{6}\right)^{2}}\right)$ (a), slant angle of the framework $\left(\alpha=2 \arcsin \left(\frac{a}{2 d_{\mathrm{Ti}-\mathrm{Ti}}}\right)\right.$ ) (b), mean length of Ti-O/F bonds (c), and mean angle between Ti-O/F bonds and (0001) plane (d). For ideal cubic $\mathrm{TiOF}_{2}, \boldsymbol{\theta}$ equals $\arcsin \sqrt{3} / 3\left(\sim 35.26^{\circ}\right)$. 


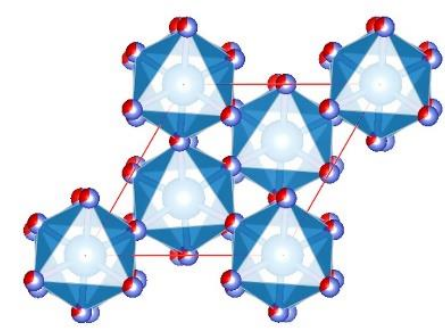

$0 \mathrm{GPa}$

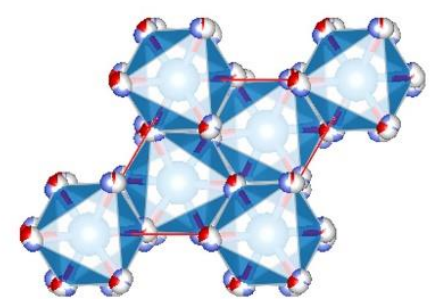

$7.57 \mathrm{GPa}$

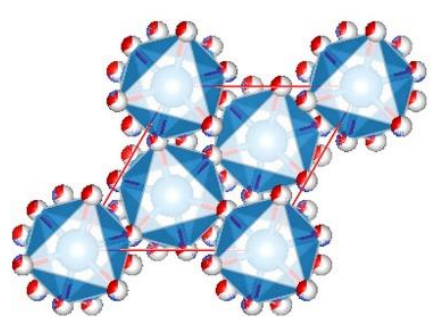

$1.44 \mathrm{GPa}$

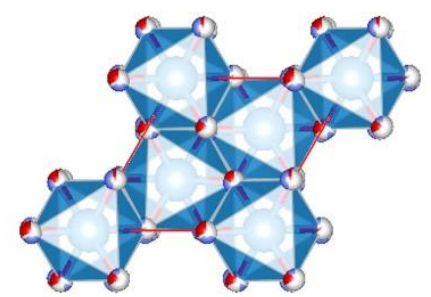

$12.80 \mathrm{GPa}$

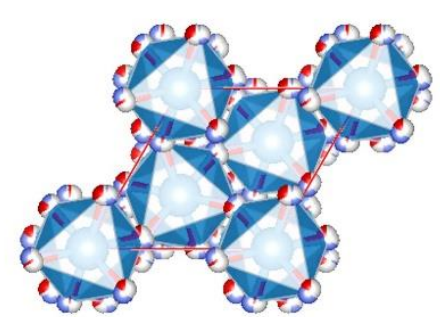

$3.40 \mathrm{GPa}$

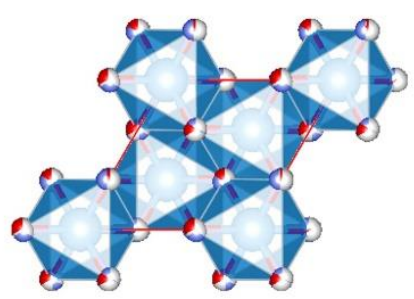

$19.92 \mathrm{GPa}$

Figure S7. Pressure-induced structural change and $\left[\mathrm{TiO}_{2} \mathrm{~F}_{4}\right]$ octahedral rotation viewed from the $[111]_{\text {Cubic }} / /[0001]_{\text {Trigonal }}$ direction. 

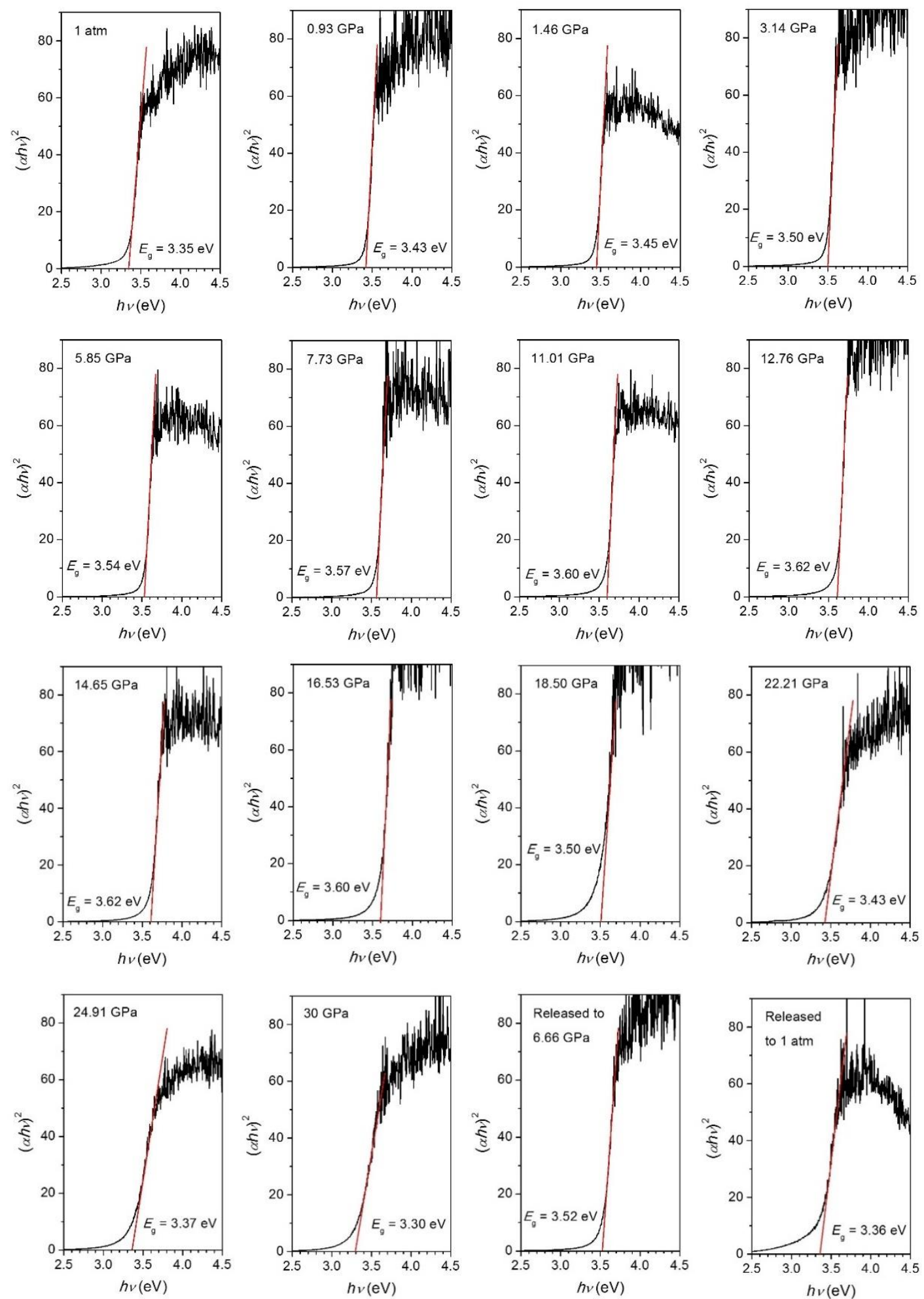

Figure S8. Tauc's plots of the absorbance data for $\mathrm{TiOF}_{2}$ sample. 


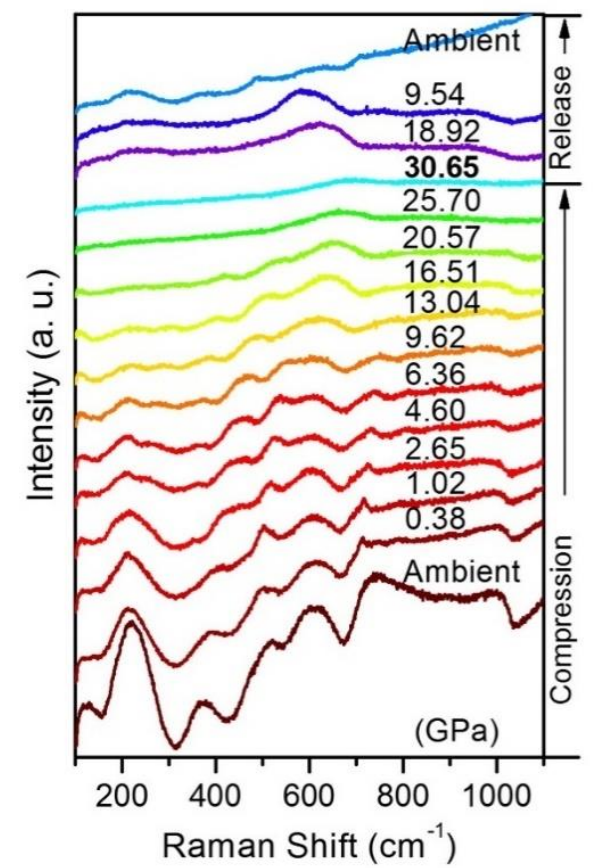

Figure S9. Selected Raman spectra of $\mathrm{TiOF}_{2}$ as a function of pressure at room temperature. 
Table S2. Compounds with NLC over a wide pressure range (>10 GPa).

\begin{tabular}{cccccccc}
\hline Compound & $\begin{array}{c}\text { Space } \\
\text { group }\end{array}$ & $\begin{array}{c}\text { Band } \\
\text { gap } \\
(\mathrm{eV})\end{array}$ & $\begin{array}{c}\text { NLC } \\
\text { value } \\
\left(\mathrm{TPa}{ }^{-1}\right)\end{array}$ & $\begin{array}{c}\text { Pressure } \\
\text { range } \\
(\mathrm{GPa})\end{array}$ & $\begin{array}{c}\text { NLC } \\
\text { axis }\end{array}$ & $\begin{array}{c}\text { Compressibility } \\
\text { capacity }(\%)\end{array}$ & Reference \\
\hline $\mathrm{TiOF}_{2}$ & 167 & 3.35 & -0.63 & $0-15$ & $c$ & 0.9 & This work \\
$\beta-\mathrm{MnO}_{2}$ & 136 & 3.54 & -0.16 & $0.3-29.3$ & $a$ & 0.5 & $1-2$ \\
$\mathrm{BPO}_{4}$ & 82 & ca. 9 & -0.92 & ca. $4-56$ & $c$ & 5.2 & $2-3$ \\
$\mathrm{BAsO}_{4}$ & 82 & -- & -1.48 & ca. $3-51$ & $c$ & 7.5 & $2-3$ \\
$\mathrm{Ag}_{3} \mathrm{PO}_{4}$ & 161 & 2.37 & -3.19 & $7.2-24.1$ & $c$ & 5.4 & 4 \\
$\mathrm{Zn}\left[\mathrm{Au}(\mathrm{CN})_{2}\right]_{2}$ & 181 & -- & -6 & $1.8-14.2$ & $c$ & 7.4 & 5 \\
\hline
\end{tabular}

\section{Reference}

(1) Haines, J.; Hoyau, S.; JM, L. Second-order rutile-type to $\mathrm{CaCl}_{2}$-type phase transition in $\beta-\mathrm{MnO}_{2}$ at high pressure. J. Phys. Chem. Solids 1995, 56 (7), 965-973.

(2) Cairns, A. B.; Goodwin, A. L. Negative linear compressibility. Phys. Chem. Chem. Phys. 2015, 17 (32), 20449-20465.

(3) Haines, J.; Chateau, C.; Leger, J. M.; Bogicevic, C.; Hull, S.; Klug, D. D.; Tse, J. S. Collapsing cristobalitelike structures in silica analogues at high pressure. Phys. Rev. Lett. 2003, $91(1), 015503$.

(4) Lu, Y.; Zhu, S.; Huang, E.; He, Y.; Ruan, J.; Liu, G.; Yan, H. Pressure-driven band gap engineering in ion-conducting semiconductor silver orthophosphate. J. Mater. Chem. A 2019, 7 (9), 4451-4458.

(5) Cairns, A. B.; Catafesta, J.; Levelut, C.; Rouquette, J.; van der Lee, A.; Peters, L.; Thompson, A. L.; Dmitriev, V.; Haines, J.; Goodwin, A. L. Giant negative linear compressibility in zinc dicyanoaurate. Nat. Mater. 2013, 12 (3), 212-6. 